
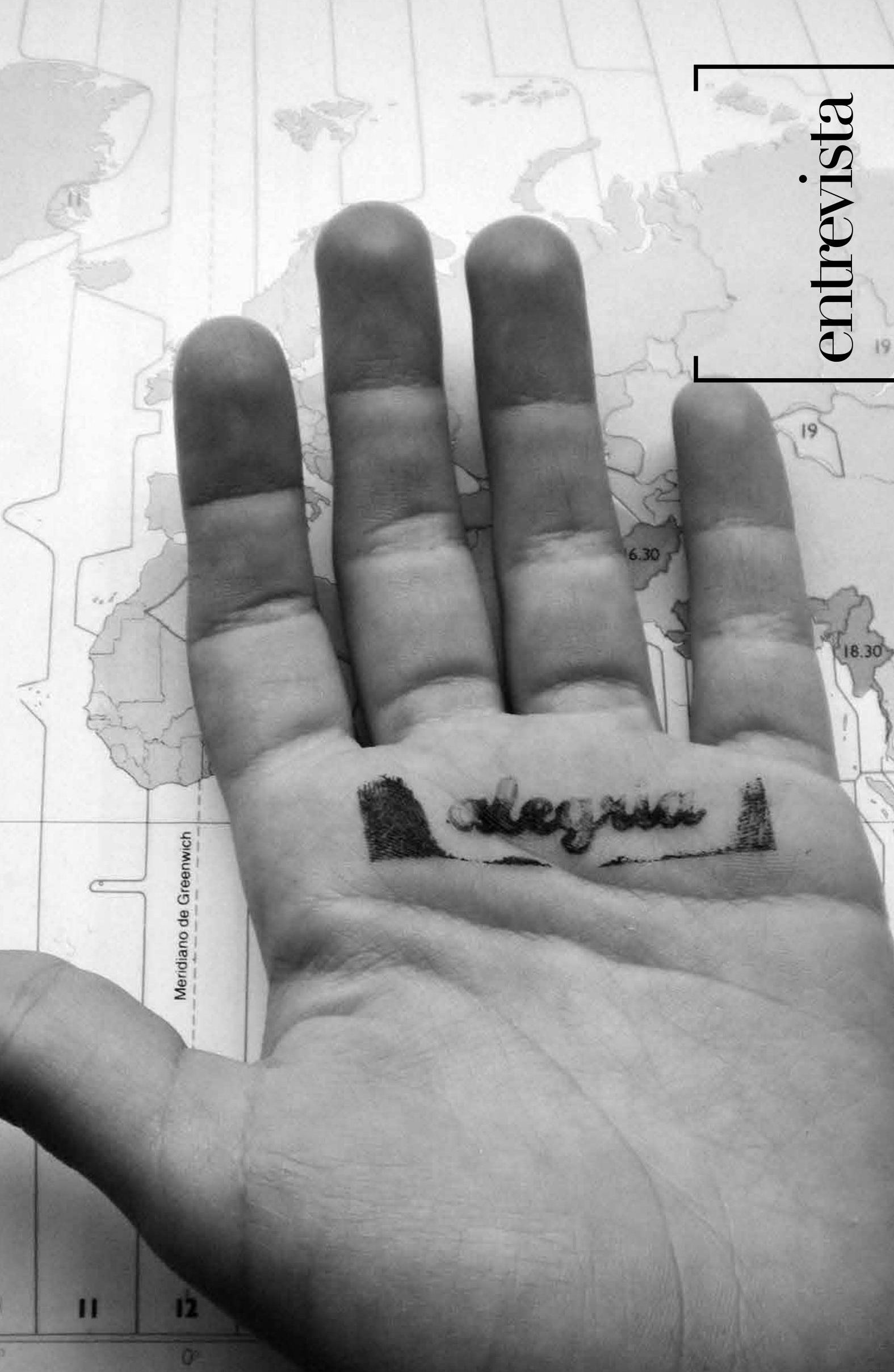
[MARIA CLAUDIA BONADIO]

Doutora em História e professora da Universidade Federal de Juiz de Fora.

E-mail: mariacbonadio@uol.com.br

[CARLOS EDUARDO PRATES]

Mestre em Moda, Cultura e Arte pelo Centro Universitário Senac.

E-mail: duduprates65@gmail.com

\section{Sobre história da moda: entrevista com}

$[66]$

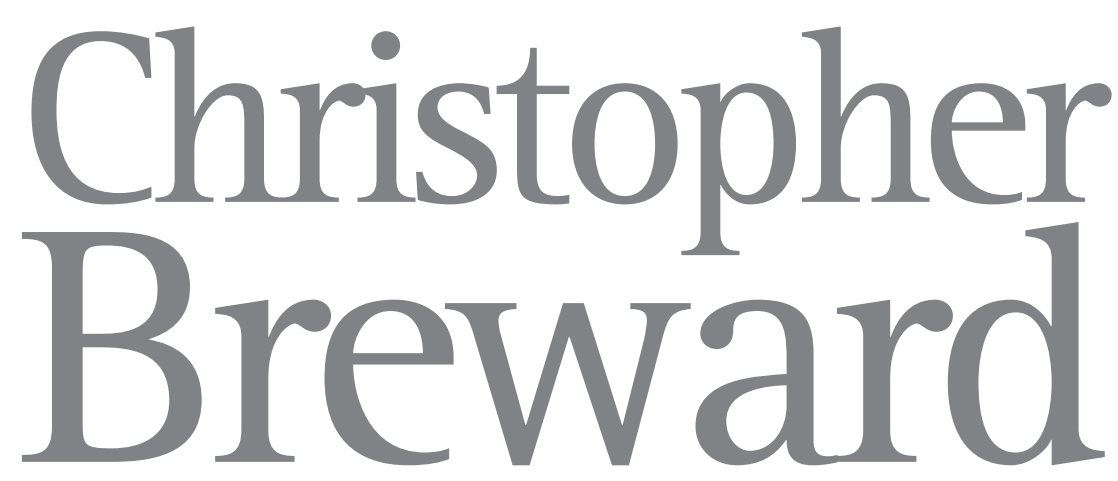

On fashion history: interview with Christopher Breward 
Christopher Breward foi um dos conferencistas do 11ํㅡㄹ Colóio de Moda ocorrido em 2015, na Universidade Positivo, em Curitiba. Aproveitando sua passagem pelo Brasil, realizamos a entrevista abaixo, cujo objetivo é apresentar ao leitor de língua portuguesa um pouco da trajetória do historiador, suas opiniões acerca do desenvolvimento dos estudos sobre história da moda nos últimos 25 anos (tempo que vem atuando na área), bem como a respeito do ensino superior na área de moda.

Com formação em história da arte e do design, desde meados dos anos 1990, Christopher Breward vem se dedicando a pesquisas sobre cultura de moda, a relação entre as cidades e a moda e história da moda masculina. Acerca desses temas, escreveu diversos livros, entre eles The Culture of Fashion: a New History of Fashionable Dress (1995), The Hidden Consumer: Masculinities, Fashion and City Life 1860-1914 (1999), Fashion (2003), Fashioning London: Clothing and the Modern Metropolis (2004) e The Suit: Form, Function and Style (lançado em abril deste ano).

Escreveu ainda diversos artigos científicos e textos para catálogos de exposições, tais como Artist, Rebel, Dandy: Man of Fashion, mostra realizada na Rhode Island School of Design, em 2013; Ivy Style (em cartaz entre 2012 e 2013); e A Queer History of Fashion (em cartaz entre 2013 e 2014), as duas últimas exposições promovidas pelo Fashion Institute of Technoloy de Nova York. Em 2012, foi um dos curadores da mostra British Design: Innovation in the Modern Age 1948-2012, realizada no Victoria Et Albert Museum, do qual foi diretor de pesquisa durante cinco anos.

Atualmente, Breward é diretor do Edinburgh College of Art, na Escócia, vice-diretor da área de indústria criativa e artes performáticas e professor de história cultural na mesma instituição.

Apesar de sua grande contribuição com os estudos da moda, há apenas dois textos de sua autoria traduzidos para o português, o artigo Bowie, a moda e a força das capas de LPs 1967-1983, publicado na versão nacional do catálogo da exposição sobre David Bowie (2014), e o prefácio que escreveu para o número especial sobre masculinidades da edição brasileira da revista científica Fashion Theory (2002). Esta entrevista pretende preencher, ainda que minimamente, essa lacuna.

Conversar com o historiador foi também uma forma de entender o desenvolvimento da história da moda como disciplina e campo de estudos, de tal modo que, para nós, a entrevista foi proveitosa. Esperamos que vocês, leitores, desfrutem da leitura!

MC - Como surgiu seu interesse por história e, sobretudo, por história da moda?

Vou contar minha biografia desde o início, pois o que vocês me perguntam é a minha história de vida! Antes de me graduar, na minha infância, nos anos 1970, eu já era fascinado pela linguagem da roupa e o que ela poderia nos contar, o que é uma história engraçada. Meu pai me sugeriu colecionar selos, quando, então, todos os meninos da minha época deviam ter esse tipo de coleção. Eu particularmente não achava a menor graça nem gostava da ideia, como também não me interessava pela coleção de selos que meu pai tinha. Nesse período, início dos anos 1970, aconteceu uma exposição de selos na cidade em que morávamos, da qual poderíamos participar expondo nossos selos e ainda concorrer a um prêmio. Na ocasião, tive a oportunidade de ver selos de vários lugares, especialmente de paises comunistas do Leste Europeu, como Hungria e outros. Havia também selos de países da América do Sul muito interessantes, com belas imagens pictóricas. Foi nesse momento que tive o desejo de criar uma história da moda para poder contá-la a partir das imagens que vi na exposição, sendo assim, reorganizei minha coleção de selos, da Idade Média aos anos 1970. Foi quando constatei a possibilidade de o historiador explorar temas históricos por meio das imagens das roupas. Talvez pelo fato da minha geração ter sido muito influenciada pela TV britânica, na qual podia-se assistir dramas históricos e seriados de romances clássicos de época - que eram os meus preferidos -, todos referentes à literatura e à história britânicas. Isso aconteceu entre os anos 1970 e 1980. Podia-se assistir 
também adaptações de Charles Dickens e de Brideshead Revisited'. Tudo isso foi uma influência muito importante para mim nesse período. Essas coisas me fascinavam, a narrativa dos personagens históricos e, mais uma vez, a moda e o figurino foram decisivos na composição emocional e psicológica dos personagens, caracterizando muito bem a época. Vejo hoje que isso fez com que eu me tornasse um historiador de arte, porque naquele período, início dos anos 1980, esse era um dos cursos que eu podia fazer, uma vez que ainda não existiam cursos de moda disponíveis no mercado. Não havia, na Inglaterra, nenhuma instituição de ensino que oferecesse o curso de História da Moda. Por essa razão, eu me formei historiador de arte. Estudei história da arte e história da arte clássica no Courtauld Institute, da Universidade de Londres, o único lugar na época no qual se podia cursar história da arte e também fazer o programa de pós-graduação em História da Moda, e Stella Mary Newton foi quem iniciou este programa, nos anos 1970, ou talvez até antes, na década de 1960. Tratava-se de um programa que incentivava os alunos a observar pinturas e analisar as vestimentas dos personagens, não porque eram o nosso foco de interesse, e sim porque, por meio delas, assegurava-se o período no qual foram retratadas e também a origem da obra. Dessa forma, poder-se-ia também definir especificamente a data e o significado correto da roupa. Com esses dados, ampliavam-se o conteúdo e a descrição sobre a história das pinturas, e isso seria moda para os historiadores de arte. Com tudo o que fiz, eu ainda não achava suficiente para mim, queria aprender mais sobre história da moda nas pinturas e como a indústria da moda funcionava. Depois de formado, atuei, por três anos, como editor, pesquisando imagens, mas não era uma atividade adequada para mim. Na segunda metade dos anos 1980, trabalhei na loja de design Conran. Por ser um trabalho que, por estar em contato com assuntos do meu interesse, como moda e estilo de vida, eu estaria próximo das minhas aptidões para moda e estilo de vida, achei que daria certo, mas não durou muito e logo fui demitido. Na sequência, fui trabalhar em uma das mais importantes livrarias de arte de Londres, situada na famosa Charing Cross Road. Lá, existia uma seção de moda, arquitetura e design, e minha função era escolher quais livros deveriam ser adquiridos por esse departamento. Naquela época, a área de publicações sobre moda estava crescendo e, só pelo fato de estar trabalhando com isso, tive um bom aprendizado sobre moda. Tornei-me um autodidata porque eu tinha um material excelente e do meu interesse a meu alcance. Ainda na livraria, soube que estava começando um programa novo do museu Victoria \&t Albert (VEtA), promovido junto com o Royal College of Art, era uma pós-graduação em História do Design. Decidi, então, sair da livraria por saber das minhas inclinações acadêmicas, e esse programa do V\&A era o meu objetivo. Foi a melhor decisão que tomei na vida. Essa pós-graduação foi especial por ter me aproximado do estudo da cultura material. 0 curso era sediado no museu, onde eu tinha acesso aos objetos de estudo - ainda sou um pouco inseguro sobre objetos, não sou curador, pois não sou capaz de entender totalmente o que um objeto tridimensional pode dizer -, o que me assustava, e também não sabia costurar e não tinha técnicas nem expertise. Mas Jules Prown, a cultura material e seus métodos me influenciaram muito e possibilitaram uma boa metodologia para pensar sobre o assunto. Por exemplo, se um vestido histórico me for apresentado, como historiador de arte, eu o vejo na sua totalidade e continuo mais interessado no que vejo do que na estrutura da peça. Dentro dessa perspectiva, tudo isso foi muito positivo, uma vez que eu estava em uma escola de arte, em contato com alunos de história da moda, onde tive a possibilidade de dar aulas sobre esse assunto; nesse momento, tive a certeza de ter encontrado a minha vocação, pois, orientando monografias de graduação, pude perceber a minha habilidade para pesquisa.

Logo depois fiz uma dissertação de mestrado sobre o início das publicações de moda para as grandes massas na Inglaterra, desde os anos 1850 até 1914 . Essa dissertação era sobre uma publicação específica para mulheres de classe média, na qual elas tinham sugestões de moda em um período complicado para a construção de gênero, e quando as revistas de moda passaram a ocupar definitivamente espaço no mercado das publicações. Obtive reconhecimento profissional por esse trabalho e fiquei obcecado pelo período de 1850 a 1914. Como eu era muito audacioso, enviei 
o trabalho para um editor que, embora tenha elogiado muito o texto, disse que só duas pessoas estariam interessadas nesse assunto, eu e minha mãe! Entretanto, ele me convidou para escrever um livro sobre cultura e história da moda direcionado para alunos de história e de moda. E esse foi o primeiro livro que escrevi, The Culture of Fashion 4 . Depois, decidi que queria me tornar professor universitário e fazer um doutorado. Primeiramente, fui trabalhar na Manchester School of Art. Contudo, eu sabia que havia espaço para publicações sobre história da moda masculina, estávamos no início dos anos 1990 e eram poucos os livros que tratavam desse assunto. Foi então que resolvi voltar para o Royal College of Art, em parceria com o V\&A, para fazer meu doutorado, que foi sobre o relacionamento do homem com a moda no século XIX em Londres. Essa tese daria início ao livro The Hidden Consumer e tratava do consumo de moda masculina, o dandismo, a masculinidade e também o considerável aumento da indústria da alfaiataria para o grande público com a promoção do estilo e as suas relações com a música e cultura popular ${ }^{5}$. Escrever esse livro foi um imenso prazer, e sempre aconselho meus orientandos a aproveitarem o máximo que puderem do período de seus doutorados, pois é muito difícil acontecer outra oportunidade de pesquisar um assunto que lhes traga tanto prazer.

Com isso, concluí que a história da moda e a história das cidades estão intrinsecamente relacionadas, no meu caso específico com Londres. Assim, notei que é possivel escrever uma história da cidade por meio da moda. Como consequência, me envolvi no London Museum (Museu de Londres), o que ocorreu no fim dos anos 1990, começo dos anos 2000. Nesse momento, acontecia uma mudança nos estudos de história da moda, que passaram a focar na questão da identidade, que começou a ser interpretada sociológica e psicologicamente. Concomitantemente, a moda também passou a ser não somente um assunto de historiadores, como dos geógrafos do Reino Unido, os quais começaram a se interessar pela moda como um fenômeno. Era uma cultura geográfica na moda e todos esses fatos me conduziram a escrever outro livro, Fashioning London, que gerou uma exposição no V\&A com foco na década de 1960. Isso me remete à masculinidade, assunto que já me interessava e que resultou no meu último livro, The Suit?

MC - Em sua opinião, qual a importância da revista Fashion Theory, lançada em 1997, para o campo dos estudos sobre moda?

Eu acho que a Fashion Theory foi uma publicação importante. Antes dela havia somente duas revistas sobre o assunto e ambas eram muito boas: Costume, no Reino Unido, e Dress, nos Estados Unidos ${ }^{8}$. A revista inglesa Costume tem aproximadamente 50 anos, quase a minha idade. Ela foi fundada em 1965 por curadores de museus e historiadores de arte, não acho justo qualificá-la de antiquada, embora muitas pessoas achassem isso. Tratava-se de uma revista com foco no objeto, nos arquivos, mas os trabalhos publicados eram rigorosos, nos quais as ciências sociais e humanas, a filosofia com suas ideias teóricas, não tinham espaço. Era uma visão sem a abertura necessária para a cultural turn ${ }^{9}$, que mudou o foco das Ciências Sociais, ou seja, para se perceber e publicar o que estava acontecendo no momento, e dar espaço para esse tipo de texto. Fashion Theory, como todos sabem, é o bebê de Valerie Steele, e ela foi pioneira com seus livros Paris Fashion e Fashion Eroticism, que muito influenciaram minha geração como modelo de conhecimento sobre moda ${ }^{10}$. Assim, Fashion Theory trouxe novos ares para as publicações sobre moda e subitamente novas vozes apareceram. Mas eu me lembro de uma conferência que aconteceu em Manchester, no Reino Unido: alguns dos trabalhos apresentados foram publicados na Fashion Theory, em um número especial sobre metodologia, e outros foram publicados na revista Costume. Esse evento representou a riqueza da interdisciplinaridade e foi promovido simultaneamente pelas duas revistas. Mas, o que aconteceu de fato ali, foi uma divergência entre os modernistas e os tradicionalistas e, de repente, eu me 
vi no meio daquela situação, muito embora eu acreditasse nas duas vertentes e simpatizasse com ambas. Na verdade, acho que a Fashion Theory foi mais importante do que qualquer outra publicação, levando-se em consideração o fato de que havia a versão em português do Brasil e também em russo, as quais incluíam trabalhos de autores norte-americanos e norte-europeus, o que abria espaço para publicações em um sentido global. Isso era realmente muito bom"1.

Agora, acho que existe um problema que vem acontecendo nos últimos cinco anos: 0 crescimento imenso de publicações sobre todos os segmentos da moda, algo em torno de 20 jornais sobre teoria da moda, o que faz com que o campo da moda se torne difuso e fragmentado de um modo geral. Acredito que esse crescimento seja bom, mas receio que ai exista o risco de se perder o rigor e a qualidade do trabalho, o que seria um enfraquecimento para essas publicações. Na verdade, sou um grande admirador da Fashion Theory, que considero um importante trabalho.

MC - A partir da sua experiência no VEtA, como você vê a relação entre moda e museu? E qual era sua função naquele museu?

Por muito tempo, o Victoria \& Albert Museum teve a sorte de ter um eficiente departamento de pesquisa, do qual eu fui diretor por cinco anos. Essa função permitia um ano sabático para todos os diretores, contudo, esse afastamento poderia se tornar uma árdua tarefa para os curadores, pois, além de trabalhar e atender o público, havia a questão da manutenção e conservação da coleção, o que acabava comprometendo o tempo da pesquisa.

Na realidade, os curadores são os melhores pesquisadores para realizar uma grande exposição, tarefa que exige tempo e estudo. Preparar uma exposição exige entre três e cinco anos aproximadamente. No caso de uma grande exposição, temos que chamar pesquisadores das universidades, de modo que eles explorem novas ideias em um contexto intelectual mais amplo, certificando-se de que assim se manterá o rigor do trabalho, a fim de que este tenha um respeitável resultado acadêmico, o que era muito benéfico para todos nós, isso também nos assegurava que as exposições do V氏tA tivessem fundamentos rigorosos de pesquisa aliados a uma interação do público em vários níveis. Acredito que essas exposições se tornaram um grande meio gerador de recursos financeiros para o museu. Podemos observar, recentemente, a exposição do McQueen, que tinha sido realizada anteriormente no Metropolitan de Nova York, e também a do David Bowie, que foi extremamente popular, atraindo muitos patrocinadores e assegurando um grande retorno financeiro com a venda de ingressos, ambas muito bem-sucedidas junto ao público ${ }^{12}$. 0 lado ruim disso tudo é que exposições relacionadas à moda nem sempre atraem grandes públicos, e nem sempre são receita de sucesso, de tal forma que glamour e celebridades podem estereotipar e levar a um entendimento equivocado do significado da moda. 0 equilíbrio entre grandes exposições e outras menos glamourosas permite que os curadores explorem diferentes aspectos do acervo do museu, o que vem ao encontro do interesse do público, que nem sempre está interessado em grandes e aclamados designers. Penso que a coleção de têxteis é a mais prejudicada com isso, não porque é um segmento esquecido, porém é menos atraente que a produção dos grandes designers. Contudo, há um volume enorme e fascinante para pesquisa dentro desse segmento, como acontece também com a moda masculina, por exemplo, que é igualmente prejudicada, uma vez que o público pensa que ela é composta apenas de ternos e isso não a torna tão sexy e atraente, devendo-se, assim, buscar um maior equilibrio entre as possibilidades. Considerando-se 0 momento atual no qual os museus sofrem com o baixo nivel de investimento dos patrocinadores, torna-se necessário promover exposições que tragam grande audiência e bom retorno financeiro. Mas o rigor deve ser mantido, o que sem dúvida é muito importante. 
Tales, em Milão, na qual analisou as capas dos LPs de David Bowie, de modo que tenho a impressão de que a cultura popular é uma influência no seu trabalho. Penso ainda que a cultura popular (ou cultura pop) é uma espécie de patrimônio cultural do Reino Unido e que os museus britânicos incorporaram a cultura pop em seus acervos e exposições, o que é possivel ver, por exemplo, em mostras como Street Style: from Sidewalk to Catwalk, 1940 from Tomorrow realizada no V氏tA entre 1994 e 1995. Como você vê a associação entre moda, cultura popular e identidade na Inglaterra e qual a importância dos estudos sobre cultura popular para o seu trabalho?

Muito importante. Fui muito influenciado por ela, mas ainda não conversamos sobre cultura popular. Todavia, penso que uma das partes mais importantes do meu trabalho foi quando pesquisei pela primeira vez as revistas femininas do século XIX, um projeto de estudo da cultura britânica, na linha do trabalho que Stuart Hall e a Birmingham School of Cultural Studies ou o British Culture Studies seguiram - os quais tornaram os estudos sobre cultura popular respeitáveis. Eram maneiras de explicar, por exemplo, por que as revistas femininas de diversos periodos tiveram seções políticas, culturais e sociais. Esse recorte teórico que é, ou foi, muito importante e tradicional no estudo de ciências humanas no Reino Unido, quando um grande número de historiadores foi influenciado por esse campo de estudo. Ao começar minha pós-graduação recebi uma lista de livros, entre os quais o mais fascinante era a obra de Dick Hebdgie, Subculture, uma das mais importantes que tínhamos que ler ${ }^{13}$. Acredito que entre os anos de 1950 e 2000 ocorreu uma forte tendência na moda britânica em conceituar a cultura popular, especialmente por meio da música e da cultura das tribos. Embora cultura popular seja um termo de difícil uso, ele evidencia as questões de identidade e, dessa forma, você [em referência a Maria Claudia Bonadio] tem razão sobre a palestra que proferi em Milão, quando fiz uma metarreflexão sobre como a cultura visual na moda, vista nas capas dos LPs de David Bowie muitas vezes esquecidas, é de extrema importância como cultura material ${ }^{14}$. Essa informação chegava aos jovens de uma Inglaterra ainda provinciana, onde não havia vida noturna nem lugares onde eles pudessem se expressar pelo seu modo de vestir, sendo assim, aqueles que já tinham atingido a maioridade não viam a hora de mudar para um grande centro, como Londres ou Manchester, para viverem essa experiência. Dessa forma, nós não damos a devida importância às capas dos LPs e às informações nelas contidas, e ainda subestimamos seu devido valor. Assim, autores dessa geração, tais como Dick Hebdgie, Stuart Hall e Angela McRobbie - escritora britânica que publicou sobre o sistema da moda e a maneira como as escolas de arte no Reino Unido decidiram deliberadamente pelo Royal College of Art, porque nele estavam inseridas a tradição e uma herança ainda da pop art dos anos 1960, do estilo e da cultura pop britânica - sempre foram importantes ${ }^{15}$. A vida nas ruas, nos ambientes privados e nos clubes noturnos, muitas vezes, torna-se difícil de traduzir para o contexto de um museu. Fazendo isso de uma maneira erra$\mathrm{da}$, o verdadeiro conceito contido nesses espaços pode ser destruido e tornar-se um objeto aprisionado em uma vitrina de museu, perdendo assim seu significado original. Geralmente, o público se emociona com o que é exibido, sendo isso um resultado positivo, como pôde ser observado no âmago da exposição de David Bowie, quando se viu claramente a sua reputação e a devoção de seus fãs. A palestra que você [Maria Claudia Bonadio] comentou sobre a capa do LPs não continha ainda a relevância que pôde ser notada na exposição de Ted Polhemus ${ }^{16}$. Essa mostra sobre street style causou uma grande controvérsia no Victoria \&t Albert Museum. Uma exposição revolucionária que provocou discussões políticas e um embate entre os curadores do VEA e Ted Polhemus, que era o curador externo. As próprias subculturas se sentiram mal representadas e divididas em categorias de tribos com as quais não concordavam. Dessa maneira, acho positivo a realização de debates e argumentos, os quais suponho serem o motivo da realização de eventos dessa natureza, assim a cultura popular tor- 
na-se algo fascinante e relevante. Outra vez, me preocupo com o esvaziamento que um evento desse porte pode ter e, ao mesmo tempo, corro o risco de parecer um velho rabugento. Ainda assim, me inquieto com o desaparecimento do senso de subcultura que podia ser visto na capa dos LPs, com isso torna-se impossível essa leitura, uma vez que esse material caiu em desuso. Estamos falando de um periodo histórico e da historicização das subculturas, assim sendo, espero que as próximas gerações sejam capazes de explicar essas mudanças que influenciaram a minha geração, como também outras que se seguiram.

MC - Alguns anos atrás você organizou o livro Fashion's World Cities, no qual a relação entre a moda e as cidades é o ponto central. 0 livro fala de diversas cidades do Leste Europeu, de países asiáticos e da África, além das já consagradas capitais da moda (Paris, Londres, Milão e Nova York), ou seja, a publicação estabelece um diálogo entre as cidades e a moda em diversas regiões do mundo, mas não há ali qualquer menção à América Latina e sobretudo ao Brasil e suas cidades da moda, São Paulo e Rio de Janeiro ${ }^{17}$. Como você explicaria essa ausência, uma vez que os outros países do BRIC (Rússia, Índia e China) estão representados no livro? E ainda, quando você pensa em moda brasileira, o que vem à sua mente?

Eu penso que são três questões: a primeira é sobre o contexto pós-colonial e 0 eterno debate sobre o que isso significa, considerando que você foi criado nesse ambiente e contesta a relação de tempo e espaço desse período, o que particularmente penso ser muito interessante. A segunda é sobre a natureza geográfica de um país com dimensões continentais e uma imensa diversidade em suas várias regiões, onde existe uma grande dificuldade para definir a história de uma determinada região sem a estereotipar, é o que acredito que ocorra no Brasil, como alguns dos seus colegas me relataram. Observo isso também quando pesquisadores europeus e norte-americanos tentam explicar do que se trata a moda brasileira. A terceira é sobre o que já haviamos discutido (e eu peço desculpas por não ter incluído o Rio ou São Paulo no livro) anteriormente sobre a noção do mundo da moda e as cidades, o que acredito ser uma construção econômica para produzir capital e vender roupas. Quando pensamos em cidades da moda do Brasil, torna-se necessário considerar fatos como haver uma semana dedicada à moda e uma cultura vibrante e muito criativa. Isso posto dentro de um contexto caracterizado por um grande fluxo de turismo, uma mídia local com conexões internacionais, em um país com economia globalizada. Dentro dessa perspectiva, fica difícil não criar estereótipos. 0 que é o caso da moda no Brasil. Vejo claramente que aqui existe um grande projeto a ser desenvolvido. Seria ótimo ver o trabalho de pesquisadores que conseguissem fazer essa conexão e evidenciar as diferenças do que é verdadeiro. Fashion's World Cities foi apenas o começo de um grande projeto que ainda está por se realizar. Posso ver isso agora, depois de uma semana em Curitiba e de uma rápida passagem pelo Rio de Janeiro durante a Fashion Rio na década passada, ou 15 anos atrás, tenho de checar. 0 que pude sentir nas conversas com alunos e professores durante o Colóquio de Moda, é que existem especificidades tanto na moda do Rio e de São Paulo quanto na de outras regiões. Isso pode ser visto de uma maneira diferente, que pode ser notado no trabalho de pesquisadores locais, e deve ser considerado mais relevante do que já foi feito em Londres, Paris, Nova York e Milão, que já é bastante conhecido. Acho que já sabemos tudo que devíamos saber sobre esse assunto, e já está estabelecido nos locais descritos como cidades da moda. Agora deveríamos discutir sobre outras regiões. No momento, estou envolvido em um projeto sobre Xangai, o que me despertou novos horizontes. Mas meu próximo grande projeto é escrever sobre a moda no século XIX, que sempre foi a minha grande paixão desde 0 início. A moda no século XVIII já foi muito pesquisada, assim como o período pós-colonial e o século XX. Já sobre o século XIX, penso que foi negligenciado, "fora de moda", e por essa razão existem poucas pesquisas sobre moda nesse período. Por isso, é necessário aprofundar-se sobre as conexões globais, entender a história global da moda no século XIX, a Era dos Grandes Impérios (mesmo que esse pareça ser um projeto ambicioso), assim como entender como a noção de "cidades da moda" foi 
construída e emergiu em um período clássico, durante o qual ocorreram o darwinismo, o marxismo e o colonialismo. Sem dúvida, a moda é uma indústria na qual podemos explorar essa visão de cultura material. Este é o meu ponto de partida, o que me possibilitará voltar ao Brasil para um melhor entendimento dessas conexões em um universo mais amplo ${ }^{18}$.

MC - Como a moda tem sido pensada nas escolas da Europa e especificamente do Reino Unido?

Existem atualmente muitos cursos de moda no Reino Unido e também acontecem muitas transformações nas universidades no contexto de ensino tanto na Europa como no Reino Unido. No momento, estão em andamento um grande debate e mudanças significativas nos cursos das universidades britânicas. 0 curso de moda é muito popular entre os jovens. Entretanto, acho que muitos deles ingressam na faculdade com um conceito equivocado, criado por uma forte campanha de mídia, no qual o trabalho com moda está relacionado a celebridades e glamour, e que trabalhando nesse segmento se tornarão designers famosos. Mas, ao mesmo tempo, pensando de uma maneira positiva, vejo, nessa geração, jovens conscientes dos desafios que irão enfrentar na sociedade contemporânea em termos ecológicos e psicológicos, em relação à sustentabilidade, às mudanças no modo de vestir dos gêneros e à exploração do trabalho escravo pela indústria da moda. Concluindo, está surgindo uma geração crítica e ciente das drásticas transformações advindas com a crescente indústria da moda nos últimos 30 anos. Isso se deve particularmente à tecnologia, e especificamente à interatividade nesse mundo competitivo que é a moda. Podemos observar a influência de blogueiros que nem sempre vivem nos grandes centros, mas mesmo assim interferem nos rumos da moda. Atualmente, os alunos são orientados a seguir duas direções: inserir-se no mercado de moda e trabalhar de forma ética e sustentável. A instituição que leciono é um caso à parte porque se trata de uma faculdade de artes com um pequeno curso de moda no contexto de uma universidade centenária, que tem foco específico em pesquisa. Assim, eu gostaria de ver alunos de moda saírem da universidade com um maior conhecimento político, social, histórico e tecnológico. Esse tipo de paradigma de mudança determina o que vem acontecendo no acesso ao conhecimento e na moda, algo que já acontece nos cursos de arquitetura, medicina e direito. Isso faz com que se tenha mais confiança, com duas condições: ter seu próprio método e sua própria tradição, mas também é necessário ter abertura para o conhecimento em economia, embora já saibamos, não podemos nos ater somente em produzir designers famosos ou pessoas por meio da moda. Com componentes tão importantes, faremos nossas vidas terem um diferencial único.

CE - Você mencionou o seu novo livro The Suit, então a nossa última questão é, o que você vem pesquisando recentemente?

Eu não quero criar expectativas para ninguém porque uma das coisas que tenho pensado muito é sobre o meu trabalho como historiador da moda há 25 anos. Observo que muitas coisas mudaram em mim, tais como meu estilo de escrever, meu senso e meu público - isto voltando a 1992, quando o editor me disse que eu escrevi somente para duas pessoas. Hoje, quando escrevo, posso causar certo espanto e digo isso para alunos que acabaram seu Ph.D. Tenho certeza de que eles pensam que estou acabado! Atualmente, quando escrevo sobre história da moda, tenho certeza de que preciso ser compreendido por um público maior, e, talvez, ter trabalhado em um museu fez com que eu entendesse isso melhor. The Suit, na realidade, é baseado no material de pesquisa que estudo há 25 anos e, por isso, posso afirmar que escrever sobre três séculos seria como reescrever mais detalhadamente sobre o significado do terno. Assim, espero ser mais acessivel e estou bastante ansioso para que a história seja lida não só por acadêmicos e, por essa razão, escrevo frases mais curtas, tento 
fazer narrativas interligadas e The Suit ainda é uma experiência de um texto redigido com notas de rodapé relativas à pesquisa primária. Acho que assim posso tornar os assuntos mais populares, e também porque estou mais velho penso dessa maneira. Quando jovem, trabalhando nos arquivos, eu era um escritor mais radical e intempestivo, agora entendo que meus antigos professores, que tinham a idade que eu tenho hoje, estavam vendendo seus livros que com certeza eram populares, e também já não mais pesquisavam nos arquivos e não eram mais tão disciplinados. Mas agora posso compreender o que eles faziam e acho que devemos treinar nossos estudantes de Ph.D., para que entendam que nem sempre as fontes estarão nos arquivos, nem sempre existirá tempo para esse tipo de pesquisa e que sua carreira seguirá etapas e se tornará mais do que uma obrigação para comunicar e orientar. No momento é 0 que estou fazendo, retornando a Uma história global da moda do século XIX, terei, novamente, a oportunidade de voltar aos arquivos para uma pesquisa de base minuciosa, mas não sei se meu cérebro será capaz de fazer as devidas conexões, pois acho que ele também deve ter mudado. Em breve veremos isto.

\section{NOTAS}

${ }^{[1]}$ Em referência à adaptação televisiva do livro Brideshead revisited, the sacred and profane memories of capt. Charles Ryde, de autoria de Evelyn Waugh publicado originalmente em 1945. A história se passa na Inglaterra e retrata o cotidiano de uma familia no periodo que antecede a Segunda Guerra e em 1981 foi adaptada para a TV no formato de seriado em 11 episódios. A série era protagonizada pelos atores Jeremy Irons e Anthony Andrews, tendo no elenco ainda Laurence Olivier, Claire Bloom e John Gielgud, entre outros. Em 2000, o seriado foi considerado o décimo melhor programa da lista dos 100 Melhores Programas da Televisão Britânica organizada por um grupo de profissionais da televisão.
\end{abstract}

[2] Possivelmente em referência ao curso de pós-graduação em História do Vestuário (History of Dress) criado e dirigido por Stella Mary Newton (1901-2001), em 1965, no Courtlaud Institute.

${ }^{[3]}$ Jules Prown (1930- ) é historiador da arte americano e entre 1964 e 1999 foi professor da Yale University, onde se aposentou com o título de professor emérito. Escreveu diversos artigos sobre cultura material e se tornou uma referência para as pesquisas na área. Entre seus livros, podemos citar Art as evidence: writings on art and material culture (2001) e American artifacts: essays in material culture (2000). Disponivel em: <https:// dictionaryofarthistorians.org/prownj.htm>. Acesso em: 28 abr. 2016.

${ }^{[4]}$ BREWARD, 1995.

[5] BREWARD, 1999.

[6] BREWARD, 2004.

[7] BREWARD, 2016.

${ }^{[8]}$ Em referência à revista cientifica Dress: the journal of the costume society of America, publicada desde 1975, ISSN 0361-2112 (Print), 2042-1729 (On-line), e Costume: the journal of the costume society, publicada desde 1966, ISSN 0590-8876 (Print), 1749-6306 (On-line).

${ }^{[9]}$ Cultural turn é a expressão usada para se referir a um movimento iniciado nas Ciências Humanas, no começo dos anos 1970, e que objetivava tornar a cultura foco dos estudos contemporâneos. Entre os principais autores que inauguraram esses estudos estão Hyden White (com o livro Meta-história: a imaginação histórica do século XIX, publicado originalmente em 1973), Cliford Geertz (com o livro A interpretação das culturas, publicado em 1973 em língua inglesa), Michel Foucault (com o livro Vigiar e punir, publicado originalmente em 1967) e Pierre Bourdieu (com o livro Razões práticas: sobre a teoria da ação, publicado originalmente em 1977).

${ }^{[10]}$ Ver: STEELE, 1985 e 1998.

${ }^{[11]}$ Circularam na Rússia 18 números da revista e a última edição naquela línqua foi publicada em 2010. Disponivel em: <http://nlobooks.ru/sites/default/files/old/nlobooks.ru/eng/111/117/125/index.html> Acesso em: 28 abr. 2016. A versão brasileira da revista foi publicada pela editora Anhembi Morumbi e organizada pela Profa. Dra. Rita Andrade de Moraes; no total foram publicados 12 números. 
${ }^{[12]}$ Em referência às exposições: Alexander McQueen: Savage Beuty, com curadoria de Andew Bolton realizada inicialmente no Metropolitan Museum de Nova York entre 4 de maio e 7 de agosto de 2011 e no Victoria \&t Albert Museum entre 14 de março e 2 de agosto de 2015. E David Bowie foi realizada no Victoria \&t Albert Museum com curadoria dos responsáveis pela seção de Teatro e Performance do Museu Victoria Broackes and Geoffrey Marsh, entre 23 de março e 11 de agosto de 2013. A exposição fez tanto sucesso que o museu apresenta uma agenda de viagem dessa exposição, já foi exibida nos paises: Canadá (2013), Brasil (2014), Alemanha (2014), Estados Unidos (2014-2015), França (2015), Austrália (2015), Nova Zelândia (2015) e seguirá ainda para o Japão em 2017. Disponivel em: <http://www.vam.ac.uk/content/articles/t/touring-exhibition-david-bowie-is/>. Acesso em: 28 abr. 2016.

[13] HEBDGIE, 1979.

${ }^{[14]}$ Fashion Tales foi um congresso internacional ocorrido entre os dias 7 e 9 de junho de 2012 em Milão, na Università Cattolica del Sacro Cuore.

${ }^{[15]}$ MCROBBIE, 1998.

${ }^{[16]}$ Antropólogo americano nascido em 1947. Autor de diversos livros sobre moda e cultura juvenil urbana e curador da exposição Street Style: From Sidewalk to Catwalk que, como citada anteriormente, foi realizada entre 1994 e 1995 no VEtA.

[17] BREWARD, 2006.

${ }^{[18]} 0$ termo "Era dos Grandes Impérios" provavelmente remete mais especificamente ao período 1875-1914, que compõe o escopo do livro A era dos impérios (1998) (cuja edição brasileira foi publicada pela editora Paz e Terra em 1988), do historiador britânico Eric Hobsbawm.

\section{REFERÊNCIAS}

BOURDIEU, Pierre. Razões práticas: sobre a teoria da ação. Campinas: Papirus, 1996.

BREWARD, Christopher (Ed.) Fashion Theory: a revista da moda, corpo e cultura, vol. 1, n. 4, 2002.

BREWARD, Christopher. Fashioning London: clothing and the modern metropolis. Oxford: Berg, 2004 Press, 1995.

The culture of fashion: a new history of fashionable dress. Manchester: Manchester University

The hidden consumer: masculinities, fashion and city life 1860-1914. Manchester: Manchester University Press, 1999.

. The suit: form, function and style. London: Reaktion Books, 2016.

BREWARD, Christopher; GILBERT, David. Fashion's world cities. Oxford: Berg, 2006.

DAVID BOWIE. São Paulo: Cosac \&t Naif, 2014.

DICTIONARY of Art Historians. Disponivel em: <https://dictionaryofarthistorians.org/prownj.htm>. Acesso em: 28 abri. de 2016.

FASHION THEORY: dress, body and culture. Disponivel em: <http://nlobooks.ru/sites/default/files/old/ nlobooks.ru/eng/111/117/125/index.html>. Acesso em: 28 abr. 2016.

FOUCAULT, Michel. Vigiar e punir: história da violência nas prisões. Petrópolis: Vozes, 1996.

GEERTZ, Cliford. A interpretação das culturas. Rio de Janeiro: Zahar, 1978.

HEBDGIE, Dick. Subculture: the meaning of style. London: Routledge, 1979.

HOBSBAWM, Eric. A era dos impérios (1875-1914). Rio de Janeiro: Paz e Terra, 1988.

MCROBBIE, Angela. British fashion design: rag trade or image industry? London: Routledge, 1998.

PROWN, Jules. Art as evidence: writings on art and material culture. Yale: Yale University Press, 2001. Press, 2000.

: HALTMANN, Kenneth (Eds.) American artifacts: essays in material culture. Michigan: MSU

STEELE, Valerie. Fashion and eroticism: ideals of feminine beauty from the victorian era through the jazz age. Oxford: Oxford University Press, 1985.

Paris fashion: a cultural history. New York: Bloomsbury Academic, 1998.

TOURING EXHIBITION: David Bowie is. Disponivel em: <http://www.vam.ac.uk/content/articles/t/

touring-exhibition-david-bowie-is/>. Acesso em: 7 abr. 2016.

WHITE, Hyden. Meta-história: a imaginação histórica do século XIX. São Paulo: Edusp, 1995. 